\title{
Catalyst-free aldol reaction of $N$-substituted rhodanines on aqueous media
}

\author{
N S DEVI and NIRADA DEVI* \\ Department of Chemistry, Cotton University, Guwahati, Assam 781 001, India \\ E-mail: niradadevicu@gmail.com
}

MS received 1 October 2017; revised 24 November 2017; accepted 22 December 2017; published online 7 February 2018

\begin{abstract}
Rhodanine derivatives are highly valuable heterocycles in drug discovery. Here, we developed aldol reaction of $N$-substituted rhodanines and aromatic aldehydes on water. The reaction was performed at room temperature affording the products in good to high yield. This synthetic protocol uses simple experimental procedures, catalyst-free, and avoids the use of highly toxic solvents.
\end{abstract}

Keywords. Rhodanines; aldol reaction; green chemistry; catalyst-free; heterocycles.

\section{Introduction}

Green chemistry is a developing new field that uses highly efficient and environmental benign synthetic protocols to minimize unnecessary environmental problems. ${ }^{1}$ The search for alternative reaction media to replace volatile organic solvents or their replacement by non-flammable, non-volatile, non-toxic and inexpensive green solvents is an important aspect of green chemistry. In this perspective, water has been used to perform organic reactions, as it is ecofriendly, cheap, non-toxic, and most abundant solvent. ${ }^{2}$ Further, water generally enables easy work-up procedure, as most organic compounds are insoluble in aqueous media. ${ }^{3}$ Therefore, the development of synthetically useful reactions in water is of considerable interest.

Compounds containing rhodanine framework possess diverse biological activities such as anti-inflamatory, ${ }^{4}$ antimalarial, ${ }^{5}$ and antibacterial activity ${ }^{6}$ (Figure 1). In particular, epalrestat is a well known drug used in the treatment of diabetic neuropathy. ${ }^{7}$ Additionally, they are known to inhibit numerous targets such as RNA polymerase, ${ }^{8} \mathrm{HIV}-1$ integrase,,${ }^{9}$ PMT1 mannosyl transferase, ${ }^{10}$ JSP-1 phosphatases, ${ }^{11}$ hepatitis C virus NS5B polymerase ${ }^{12}$ and cathepsin D. ${ }^{13}$ Due to high potential of rhodanine derivatives in drug discovery, there is growing interest to devise a rapid and clean method for their synthesis.
Various methods have been developed for the synthesis of rhodanine derivatives. ${ }^{14}$ Among them, $N$ substituted-5-arylidene rhodanine derivatives have been prepared by condensation of rhodanine and aromatic aldehyde in basic reaction conditions. On the other hand, catalytic aldol reaction is very common in organic solvents and aqueous medium ${ }^{15-17}$ whereas catalyst-free aldol reactions are rare. ${ }^{18}$ The reaction of rhodanine and aromatic aldehyde failed to give aldol adducts due to subsequent dehydration of aldol product to $\mathrm{N}$ substituted-5-arylidene rhodanines under basic reaction conditions (Scheme 1i). ${ }^{19}$ We expect that the reaction of rhodanine with aromatic aldehyde under catalyst-free condition may give aldol product.

\section{Experimental}

\subsection{Materials and methods}

All the compounds were commercial grade and used without further purification. Melting points (m.p.) were determined on a Thomas Hoover melting point apparatus and are uncorrected. Analytical TLC was performed on readymade silica gel plates (Merck); visualization was accomplished with UV light and iodine. IR spectra were recorded on an FT-IR PerkinElmer spectrometer and are reported as wavelength number $\left(\mathrm{cm}^{-1}\right) .{ }^{1} \mathrm{H}$ NMR and ${ }^{13} \mathrm{C}$ NMR spectra were recorded at 400 and $100 \mathrm{MHz}$ in $\mathrm{CDCl}_{3}$. Chemical shifts are reported with

\footnotetext{
*For correspondence

Electronic supplementary material: The online version of this article (https://doi.org/10.1007/s12039-018-1419-2) contains supplementary material, which is available to authorized users.
} 


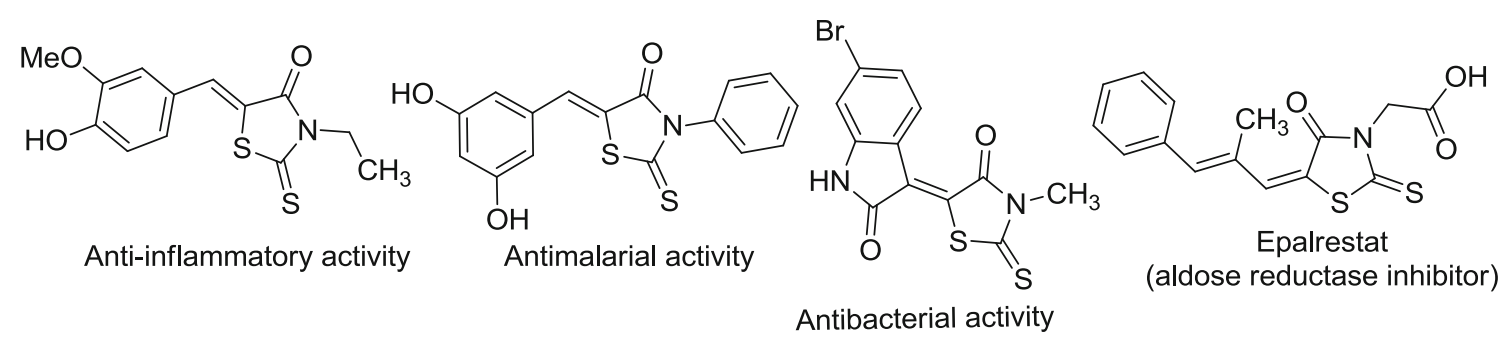

Figure 1. Bioactive compounds containing rhodanine framework.

\section{Reported method}<smiles>[R][X]c1ccc(C=O)cc1</smiles>

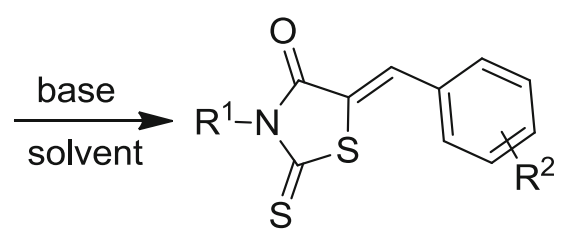

(i)

\section{Present work}<smiles>[R][X]c1ccc(C=O)cc1</smiles>

Scheme 1. Reaction of rhodanine and aromatic aldehyde.

reference to TMS as internal standard. Mass spectra were recorded ESI mode (Q-TOF type Mass Analyzer).

\subsection{General procedure for the synthesis of rhodanine derivatives $(3 a-3 j)$}

A heterogeneous mixture of 3-substituted-2-thioxothiazolidin-4-one (1) $(0.5 \mathrm{mmol})$, aromatic aldehyde (2) $(0.6 \mathrm{mmol})$ and water $(5 \mathrm{~mL})$ was stirred at room temperature. After $24 \mathrm{~h}$ stirring, reactants (1) and (2) becomes yellowish gummy solid. The reaction was monitored by TLC (a small amount of the gummy solid was removed and dissolved in ethyl acetate). Upon completion of the reaction, the reaction mixture was worked up with ethyl acetate ( 2 times $5 \mathrm{~mL}$ ). The organic layer was collected, washed with water (10 times $2 \mathrm{~mL}$ ), dried with anhydrous $\mathrm{Na}_{2} \mathrm{SO}_{4}$, and concentrated to give crude residue, which was subjected to silica gel chromatography (10\% EtOAc/in hexane) as eluent to give the product (3a-3j).

\section{Results and Discussion}

With this curiosity in mind and taking cues from the catalyst-free aldol reaction, a trial reaction was performed by treating 3-methyl-2-thioxo-thiazolidin-4-one (1a) and $p$-nitro benzaldehyde (2a) without any catalyst on water (Table 1, entry 1). After $24 \mathrm{~h}$ stirring at room temperature, a new product was observed (monitored by TLC). The product was isolated by column chromatography in $75 \%$ yield and identified the product as 5-(hydroxyl (4-nitrophenyl)methyl)-3-methyl-2thioxothiazolidin-4-one (3a) on the basis of spectroscopic analysis $\left({ }^{1} \mathrm{H}\right.$ NMR, ${ }^{13} \mathrm{C}$ NMR, IR, HRMS $)$. In compound (3a), the signal at $\delta=2.75 \mathrm{ppm}$ showed the presence of $-\mathrm{OH}$ and doublet at $\delta=4.55 \mathrm{ppm}$ indicated the presence of methine proton of rhodanine ring in its ${ }^{1} \mathrm{H}$ NMR. ${ }^{13} \mathrm{C}$ NMR spectrum showed the signal at $\delta=58.8 \mathrm{ppm}$ for methine carbon of rhodanine ring while the signal at $\delta=71.3 \mathrm{ppm}$ for methine carbon outside the rhodanine ring. In addition, the signals at $\delta=174.3 \mathrm{ppm}$ and $\delta=200.1 \mathrm{ppm}$ show the presence of carbonyl and thiocarbonyl carbon in its ${ }^{13} \mathrm{C}$ NMR.

Encouraged by this unique aldol reaction, further optimization reactions were performed by varying reaction parameters to attain the best yield of the product. When the reaction time was continued for $48 \mathrm{~h}$, no further improvement in the yield was observed (Table 1, entry 2). Then, the effect of different solvents was screened. In polar aprotic solvents such as DMSO and DMF, this reaction afforded high yield of the product 
Table 1. Optimization of reaction conditions.

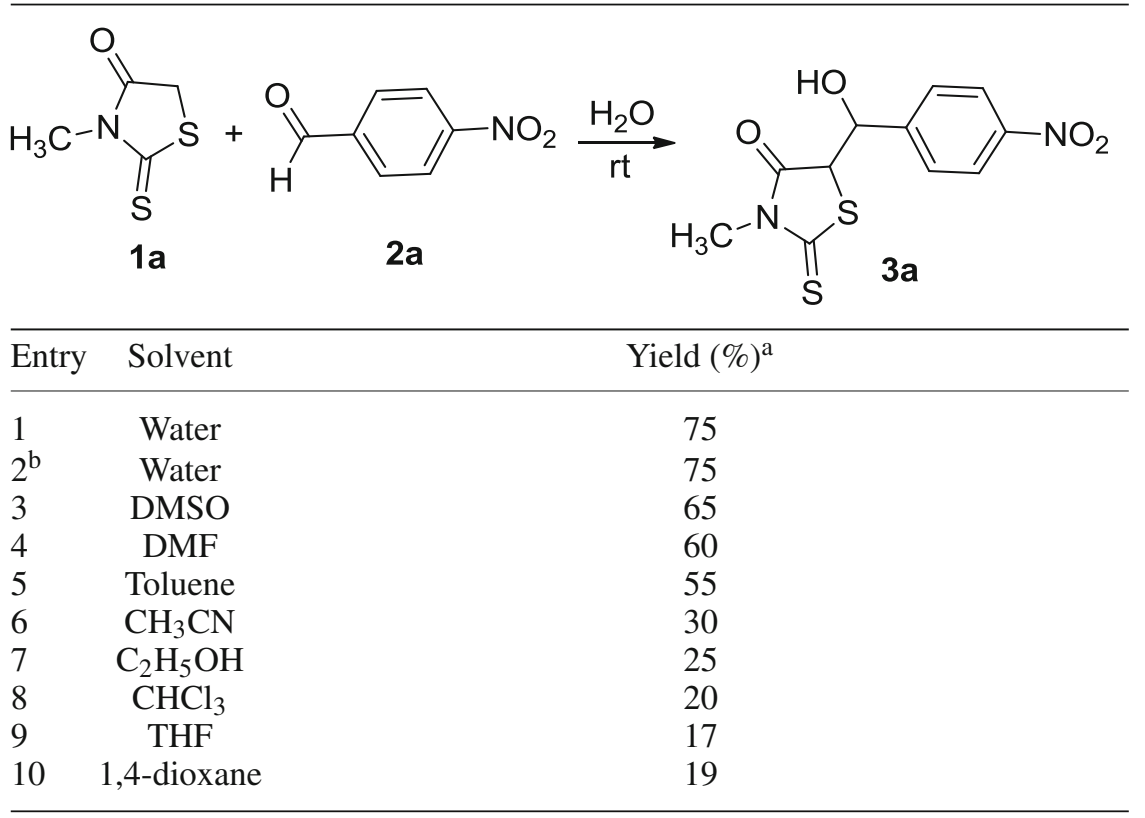

Reaction conditions: 3-methyl-2-thioxo-thiazolidin-4-one (1a) (0.5 mmol), p-nitro benzaldehyde (2a) $(0.6 \mathrm{mmol}), \mathrm{rt}, 24 \mathrm{~h}$.

${ }^{\text {a }}$ Isolated yield based on (1a).

${ }^{b}$ Reaction mixture stirred for $48 \mathrm{~h}$.

(Table 1, entries 3-4). Moderate yield was observed using toluene (Table 1, entry 5), whereas in case of acetonitrile, ethanol, chloroform, THF and 1, 4-dioxane (entries 6-10), the reaction provided very low yield. Among the solvent studied, water was found to be the best media for this reaction. Thus the optimized reaction condition for aldol reaction was obtained by using 3-methyl-2-thioxo-thiazolidin-4-one $(0.5 \mathrm{mmol})$ and $p$-nitro benzaldehyde $(0.6 \mathrm{mmol})$ in water at room temperature for $12 \mathrm{~h}$.

To further broaden the scope of the aldol reaction, various $N$-substituted rhodanines and aromatic aldehydes were examined as shown in (Table 2). The $N$-methyl substituted rhodanine (1a) condensed with aromatic aldehyde bearing electron withdrawing groups at different position such as $4-\mathrm{NO}_{2}(\mathbf{2 a}), 3-\mathrm{NO}_{2}(\mathbf{2 b})$, 2- $\mathrm{NO}_{2}$ (2c), and 4-CN (2d) gave their corresponding aldol product (3a) (75\%), (3b) (63\%), (3c) (59\%), and (3d) $(69 \%)$ in moderate to high yield (Table 2). The trends in the reactivity of substituted aromatic aldehydes were observed; the electron-withdrawing group in para-position of aromatic aldehydes gave higher yield of the product as compared to their corresponding meta and ortho position at aromatic aldehydes. A moderate yield of the products were observed when $N$-benzyl substituted rhodanines (1b) react with 4nitrobenzaldehyde (2a), and 3-nitro benzaldehyde (2b).
However, a low yield (40\%) was observed while using 4-chlorobenzaldehyde.

Similarly, rhodanine (1c) can react with aromatic aldehyde bearing electron withdrawing groups such as 4- $\mathrm{NO}_{2}(\mathbf{2 a}), 3-\mathrm{NO}_{2}(\mathbf{2 b})$, and 2- $\mathrm{NO}_{2}(\mathbf{2 c})$ to give their corresponding aldol products $\mathbf{3 h}, \mathbf{3 i}$ and $\mathbf{3} \mathbf{j}$ in moderate to good yield. In this case also, the electron withdrawing group in para-position of aromatic aldehydes gave higher yield of the product as compared to their corresponding meta and ortho position. As expected, $N$ phenyl substituted rhodanine (1d) also reacts with (2a) gave the desired product in $60 \%$ yield. However, benzaldehyde or its electron donating substituents such as $-\mathrm{CH}_{3}$ and $-\mathrm{OCH}_{3}$ at any position cannot undergo aldol reaction. The reaction fails for longer reaction time or thermal condition.

Based on the literature, ${ }^{15}$ the mechanistic pathway for this reaction is shown in Scheme 2. The hydrogen bonding plays a significant role in the aldol reaction between rhodanine and aldehyde. ${ }^{18 \mathrm{e}}$ The hydrogen bonding brings both the reactants close together and enhances the nucleophilicity of the rhodanine and electrophilicity of the benzaldehyde. The rhodanine (1a) exists in equilibrium with the enol form (A) in the presence of water. The enol form (A) will attack to carbonyl carbon of 4-nirobenzaldehyde (2a) to form aldol product (3a). 
Table 2. Aldol reaction of $N$-substituted rhodanine.

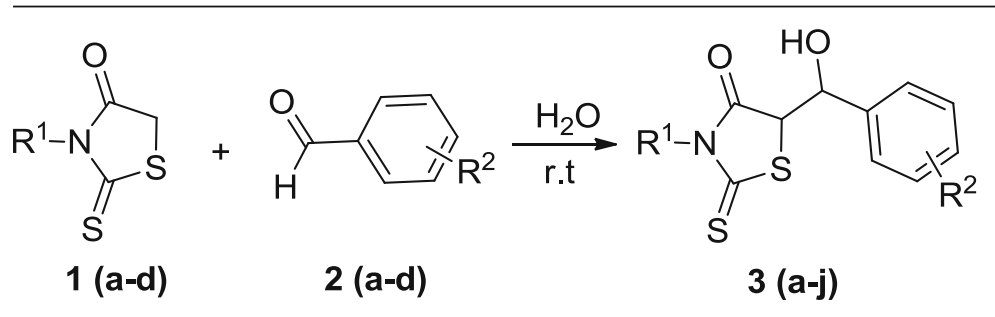

\begin{tabular}{|c|c|c|c|c|}
\hline Entry & $\mathrm{R}^{1}$ & $\mathrm{R}^{2}$ & Product & Yield $(\%)^{\mathrm{a}}$ \\
\hline 1 & $\mathrm{CH}_{3}$ & $4-\mathrm{NO}_{2}$ & $23 a$ & 75 \\
\hline 2 & $\mathrm{CH}_{3}$ & $3-\mathrm{NO}_{2}$ & $23 b$ & 63 \\
\hline 3 & $\mathrm{CH}_{3}$ & $2-\mathrm{NO}_{2}$ & $23 c$ & 59 \\
\hline 4 & $\mathrm{CH}_{3}$ & $4-\mathrm{CN}$ & $3 d$ & 69 \\
\hline 5 & $\mathrm{C}_{6} \mathrm{H}_{5} \mathrm{CH}_{2}$ & $4-\mathrm{NO}_{2}$ & $23 e$ & 65 \\
\hline 6 & $\mathrm{C}_{6} \mathrm{H}_{5} \mathrm{CH}_{2}$ & $3-\mathrm{NO}_{2}$ & $23 \mathrm{f}$ & 62 \\
\hline 7 & $\mathrm{C}_{6} \mathrm{H}_{5} \mathrm{CH}_{2}$ & $4-\mathrm{Cl}$ & $3 g$ & 40 \\
\hline 8 & $4-\mathrm{OCH}_{3} \mathrm{C}_{6} \mathrm{H}_{4} \mathrm{CH}_{2}$ & $24-\mathrm{NO}_{2}$ & $23 \mathrm{~h}$ & 67 \\
\hline 9 & $4-\mathrm{OCH}_{3} \mathrm{C}_{6} \mathrm{H}_{4} \mathrm{CH}_{2}$ & $23-\mathrm{NO}_{2}$ & $3 \mathrm{i}$ & 55 \\
\hline 10 & $4-\mathrm{OCH}_{3} \mathrm{C}_{6} \mathrm{H}_{4} \mathrm{CH}_{2}$ & $2-\mathrm{NO}_{2}$ & $3 \mathrm{j}$ & 50 \\
\hline 11 & $\mathrm{C}_{6} \mathrm{H}_{5}$ & $4-\mathrm{NO}_{2}$ & $23 \mathrm{k}$ & 60 \\
\hline
\end{tabular}

Reaction conditions: $N$-substituted rhodanine (1) $(0.5 \mathrm{mmol})$, aromatic aldehyde (2) $(0.6 \mathrm{mmol}), \mathrm{rt}, 24 \mathrm{~h}$.

${ }^{a}$ Isolated yield based on (1).
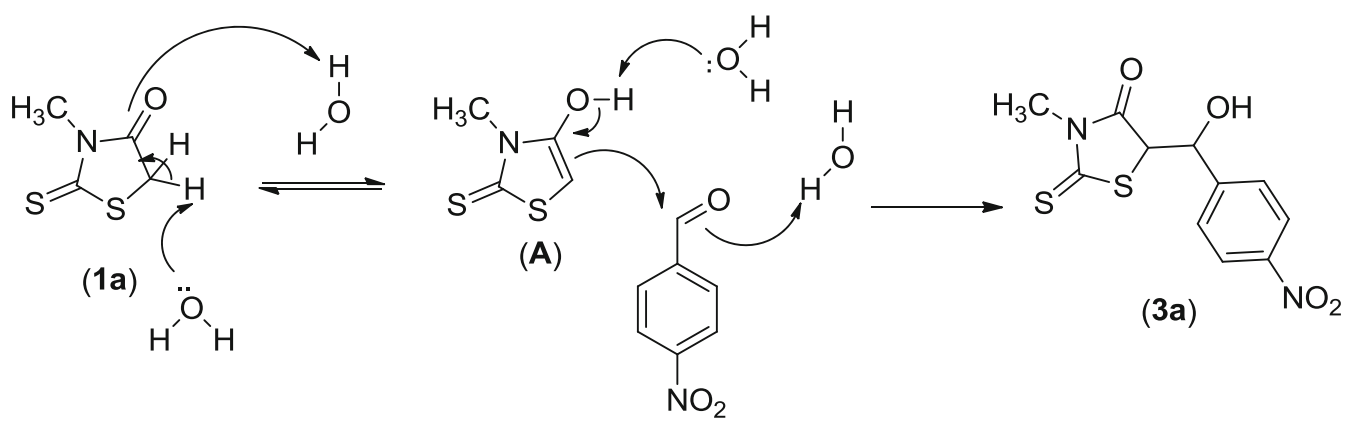

Scheme 2. Proposed mechanism for aldol reaction between rhodanine and aromatic aldehyde in water.

\section{Conclusions}

In conclusion, we have successfully described the aldol reaction of $N$-substituted rhodanines and aromatic aldehydes on aqueous medium. This newly developed procedure offers several advantages including high yield, mild reaction conditions, and environmental friendliness.

\section{Supplementary Information (SI)}

Full characterization details, NMR $\left({ }^{1} \mathrm{H}\right.$ and ${ }^{13} \mathrm{C}$ NMR spectra, HRMS data for all the compounds are presented in Supplementary Information, which is available at www.ias.ac.in/ chemsci.

\section{Acknowledgements}

The authors acknowledge the support of this research by the Science and Engineering Research Board (SERB) (SB/FT/ CS-170/2013), New Delhi, India. Authors are also thankful to Central Instruments Facility (CIF), IIT Guwahati, for spectral recording.

\section{References}

1. Anastas P T and Warner J C 2000 Green Chemistry: Theory and Practice (Oxford: Oxford University Press)

2. (a) Mehra M K, Tantak M P, Arun V, Kumar I and Kumar D 2017 Metal-free regioselective formation of $\mathrm{C}-\mathrm{N}$ and $\mathrm{C}-\mathrm{O}$ bonds with the utilization of diaryliodonium salts in water: Facile synthesis of $N$-arylquinolones and aryloxyquinolines Org. Biomol. Chem. 15 4956; (b) Lindstrom U M 2002 Stereoselective organic reactions in water Chem. Rev. 1022751 
3. Chanda A and Fokin V V 2009 Organic synthesis "on water" Chem. Rev. 109725

4. Irvine M W, Patrick G L, Kewney J, Hastings S F and Mackenzie S J 2008 Rhodanine derivatives as novel inhibitors of PDE4 Bioorg. Med. Chem. Lett. 182032

5. Silva A A R, Góes A J S, Lima W T and Maia M B S 2003 Antiedematogenic activity of two thiazolidine derivatives: $N$-Tryptophyl-5-(3,5-di-tert-butyl-4-hydroxyben zylidene) Rhodanine (GS26) and $N$-Tryptophyl-5-(3,5di-tert-butyl-4-hydroxybenzylidene)-2,4-thiazolidinedi one (GS28) Chem. Pharm. Bull. 511351

6. Inamori Y, Okamoto Y, Takegawa Y, Tsujibo H, Sakagami Y, Kumeda Y, Shibata M and Numata A 1998 Insecticidal and antifungal activities of aminorhodanine derivatives Biosci. Biotechnol. Biochem. 621025

7. Terashima H, Hama K, Yamamoto R, Tsuboshima M, Kikkawa R, Hantanaka I and Shigeta Y 1984 Effects of a new aldose reductase inhibitor on various tissue in vitro J. Pharmacol. Exp. Ther. 229226

8. Villain-Guillot P, Gualtieri M, Bastide L, Roquet F, Martinez J, Amblard M, Pugniere M and Leonetti J-P 2007 Structure-activity relationships of phenylfuranyl-rhodanines as inhibitors of RNA polymerase with antibacterial activity on biofilms J. Med. Chem. $\mathbf{5 0}$ 4195

9. Dayam R, Sanchez T, Clement O, Shoemaker R, Sei $\mathrm{S}$ and Neamati N $2005 \beta$-Diketo acid pharmacophore hypothesis. 1. Discovery of a novel class of HIV-1 integrase inhibitors J. Med. Chem. 48111

10. Sing W T, Lee C L, Yeo S L, Lim S P and Sim M M 2001 Arylalkylidene rhodanine with bulky and hydrophobic functional group as selective HCV NS3 protease inhibitor Bioorg. Med. Chem. Lett. 1191

11. Grant E B, Guiadeen D, Baum E Z, Foleno B D, Jin H, Montenegro D A, Nelson E A, Bush K and Hlasta D J 2000 The synthesis and SAR of rhodanines as novel class C $\beta$-lactamase inhibitors Bioorg. Med. Chem. Lett. 102179

12. Talele T T, Arora P, Kulkarni S S, Patel M R, Singh S, Chudayeu M and Basu N K 2010 Structure-based virtual screening, synthesis and SAR of novel inhibitors of hepatitis C virus NS5B polymerase Bioorg. Med. Chem. Lett. 184630

13. Whitesitt C A, Simon R L, Reel J K, Sigmund S K, Phillips M L, Shadle J K, Heinz L J, Koppel G A, Hunden D C, Lifer S L, Berry D, Ray J, Little S P, Liu X, Marshall W S and Panetta J A 1996 Synthesis and structure-activity relationships of benzophenones as inhibitors of cathepsin D Bioorg. Med. Chem. Lett. 6 2157
14. (a) Rostamnia S, Zeynizadeh B, Doustkhah E, Baghban A and Aghbash K O 2015 The use of $\kappa$ carrageenan $/ \mathrm{Fe}_{3} \mathrm{O}_{4}$ nanocomposite as a nanomagnetic catalyst for clean synthesis of rhodanines Catal. Commun. 68 77; (b) Rostamnia S, Doustkhah E and Nuri A 2013 Hexafluoroisopropanol dispersed into the nanoporous SBA-15 (HFIP/SBA-15) as a rapid, metalfree, highly reusable and suitable combined catalyst for domino cyclization process in chemoselective preparation of alkyl rhodanines J. Fluor. Chem. 153 1; (c) Alizadeh A, Rostamnia S, Zohreh N and Hosseinpour R 2009 A simple and effective approach to the synthesis of rhodanine derivatives via three-component reactions in water Tetrahedron Lett. 50 1533; (d) Rostamnia S 2011 A rapid, catalyst-free, three-component synthesis of rhodanines in water using ultrasound Synthesis 2011 3080; (e) Metwally M A, Etman H A, KeshkE M and Fekry A 2006 Thiazolidin-5-ones: Synthesis and reactions Phosphorus Sulfur 181 1039; (f) Mulay A, Mangesh G and Nikalje A P 2009 Exploring potential of 4-thiazolidinone: A brief review Int. J. Pharm. Sci. 146

15. List B 2002 Proline-catalyzed asymmetric reactions Tetrahedron 585573

16. Schetter B and Mahrwald R 2006 Modern aldol methods for the total synthesis of polyketides Angew. Chem. Int. Edit. 457506

17. Trost B M and Brindle C S 2010 The direct catalytic asymmetric aldol reaction Chem. Soc. Rev. 391600

18. (a) Rohr K and Marhrwald R 2008 Catalyst-free aldol additions of 1,3-dicarbonyl compounds Adv. Synth. Catal. 350 2877; (b) Curtimgrt C, Battistini L, Zanardi F, Rassu G, Zambrano V, Pinna L and Casiraghi G 2010 Uncatalyzed, diastereoselective vinylogous Mukaiyama aldol reactions on aqueous media: Pyrrole vs furan 2-silyloxy dienes J. Org. Chem. 75 8681; (c) Sartori A, Dell'Amico L, Curti C, Battistini L, Pelosi G, Rassu G, Casiraghi G and Zanardi F 2011 Aqueous and solvent-free uncatalyzed three-component vinylogous mukaiyama-mannich reactions of pyrrole-based silyl dienolates Adv. Synth. Catal. 353 3278; (d) Paladhi S, Bhati M, Panda D and Dash J 2014 thiazolidinedioneisatin conjugates via an uncatalyzed diastereoselective aldol reaction on water J. Org. Chem. 79 1473; (e) Paladhi S, Chauhan A, Dhara K, Tiwari A K and Dash J 2012 An uncatalyzed aldol reaction of thiazolidinediones Green Chem. 142990

19. Lesyk R B and Zimenkovsky B S 2004 4-Thiazolidones: centenarian history, current status and perspectives for modern organic and medicinal chemistry Curr. Org. Chem. 81547 